\title{
Os Pais e a Transição do Jovem para a Vida Adulta
}

\author{
Clarissa Magalhães Rodrigues \\ Ida Kublikowski \\ Pontificia Universidade Católica de São Paulo \\ São Paulo, SP, Brasil
}

\begin{abstract}
RESUMO
Este artigo apresenta os resultados de uma pesquisa qualitativa cujo objetivo consistiu em compreender, sob a Psicologia Sistêmica, o modo como pais percebem seus filhos em transição para a vida adulta. Quatro casais e três mães solteiras oriundos de famílias paulistas e com filhos entre 25 e 30 anos responderam a entrevistas semiestruturadas, tendo-se realizado uma entrevista para cada família representada. Os resultados indicaram que a relativização da importância do casamento, da independência financeira e da saída do lar parental como marcos normativos de transição para a vida adulta favorece um novo olhar sobre a adultez, que passa a ser compreendida como resultado de um processo pautado no valor moral da responsabilidade e na maturidade da interdependência. Por outro lado, visões ambivalentes quanto à condição adulta de alguns dos filhos lembram que a construção da identidade adulta pressupõe uma transição entre fases do ciclo vital familiar, exigindo a ressignificação da parentalidade.
\end{abstract}

Palavras-chave: Família; Parentalidade; Juventude.

\section{ABSTRACT}

\section{The Parents and the Transition of Youngsters into Adulthood}

This article presents the results of a qualitative research aimed to understand, from a Systemic Psychology standpoint, the way parents perceive their children in transition into adulthood. Four couples and three single mothers from São Paulo state, and whose children were between 25 and 30 years old, answered semi-structured interviews, with one interview for each represented family. Results indicated that the relativization of marriage, financial independence, and the leaving of parents' home as normative landmarks for the transition into adulthood favor a new conception of being an adult, which turns out to be considered as the result of a process conducted by the moral value of responsibility and by the maturity of interdependence. On the other hand, ambivalent visions on the adult condition of some children highlight the fact that the development of adult identity implies a transition between distinct phases of the family life cycle, demanding the re-signification of parenting itself.

Keywords: Family; Parenting; Young adults.

\section{RESUMEN}

Los Padres y la Transición del Joven para la Vida Adulta

Este artículo presenta los resultados de una investigación cualitativa cuyo objetivo consistió en comprender, bajo la Psicología Sistémica, el modo como los padres con hijos en transición para la vida adulta perciben las mudanzas reveladas por sus descendientes. Cuatro matrimonios y tres madres solteras del Estado de São Paulo, y com hijos entre los 25 y los 30 años, respondieron a entrevistas semi-estructuradas, siendo una entrevista para cada una de las familias. Los resultados indicaron que la relativización del casamiento, de la independencia financiera y de la salida del hogar parental como marcos normativos de transición favorecen una nueva visión sobre la fase adulta, ahora comprendida como resultado de un proceso construido sobre el valor de la responsabilidad y de la maturidad de la interdependencia. Por otro lado, una comprensión ambivalente en cuanto a la condición adulta de algunos hijos recuerda que la construcción de la madurez presupone una transición entre fases del siglo vital familiar y exige un nuevo significado para la paternidad.

Palavras-clave: Familia; Paternidad; Jóvenes. 


\section{UM NOVO CONTEXTO DE TRANSIÇÃO PARA A VIDA ADULTA}

O tema da transição para a vida adulta tem sido objeto de investigação acadêmica nas ciências humanas e sociais, situado em um novo contexto para o desenvolvimento humano. A multiplicidade de trajetórias possíveis para a adultez (Camarano, 2006), as concepções acerca do que é ser adulto (Boeing, 2011), a "geração canguru" e o "ninho cheio" (Borges \& Magalhães, 2009), dentre outros recortes temáticos, figuram em um novo cenário reconhecido pelo alto desenvolvimento tecnológico e pela transformação nas relações de intimidade (Giddens, 1993).

Se, de um lado, a proliferação de novas tecnologias passou a exigir maiores investimentos em estudos, não raro adiando o ingresso do jovem no mercado de trabalho e prolongando sua dependência econômica em relação à família de origem (Papalia, Olds, \& Feldman, 2010), de outro abalou a hierarquia entre pais e filhos, aproximando-os por meio do acesso simultâneo de ambas as gerações a um mesmo objeto de conhecimento: as incessantes novidades tecnológicas (Romanelli, 2003). Esse movimento de aproximação veio somarse ao que Zanetti e Gomes (2009) identificaram como uma desqualificação do saber natural dos pais em detrimento dos saberes especializados, calcados no desenvolvimento científico positivista, e com base nos quais se difundiram ensinamentos comportamentais associados a modelos ideais de educação, contribuindo para uma fragilização da autoridade parental na família brasileira contemporânea. Além disso, com o movimento feminista, na década de 1970, a conquista de um status social feminino mais horizontalizado em relação aos homens potencializou a democratização nas relações de gênero, refletindo-se, segundo Giddens (1993), sobre a vivência da sexualidade e sobre a natureza do casamento: enquanto a primeira ganhou em liberdade, desvinculando-se de uma função eminentemente reprodutiva, a segunda passou, segundo Hime (2004), a dever "acolher as necessidades de autonomia, afirmação de si e também de construir uma relação satisfatória, que integre amor e sexo" (p.132).

A satisfação erigiu, portanto, como condição relevante para a manutenção das uniões civis, e o retorno à casa dos pais em decorrência de separações e divórcios tornou-se aceitável, já que a coabitação entre pais e filhos adultos constitui, hoje, realidade não incomum nas famílias brasileiras (Henriques, FéresCarneiro, \& Ramos, 2011). Esse retorno ao lar parental configura, segundo Pais (2005), as trajetórias "ioiô", motivadas não apenas pelo divórcio, mas também pelo desemprego ou pela necessidade de o jovem investir seus ganhos financeiros em maior qualificação profissional.

Em meio a mudanças políticas que conferiram maior liberdade aos jovens no ocidente, o compartilhamento de novidades tecnológicas entre as gerações vem resultando em um novo modelo de relação intergeracional (Giddens, 1993). Nele, a autoridade dos pais, antes presumida em função da idade e do acúmulo de experiências, hoje se acha em larga medida substituída pela intimidade e pela conquista de confiança, configurando-se entre pais e filhos modelos relacionais menos hierárquicos. Para Szapiro e Resende (2010), esse novo modelo coloca os jovens em uma "situação simbólica de abandono" (p. 45), motivada pela dificuldade dos pais em desempenhar o papel de promotores da segurança emocional que deveria fazer da família o lócus de base para a construção de identidades razoavelmente seguras. Assim, a transição para a vida adulta, hoje ambientada em um novo cenário de maiores possibilidades e menos garantias, coloca desafios para os pais cujos filhos efetuam esse percurso, na medida em que parece exigir das figuras parentais o difícil empreendimento de, buscando lidar com as descontinuidades e incertezas da vida, manterse como referência e apoio para seus descendentes.

Tal dificuldade parece agravar-se, ainda, em função de uma menor clareza quanto às tarefas desenvolvimentais socialmente requeridas para a legitimação da condição adulta, dada a pluralidade de trajetórias possíveis de transição para a adultez na contemporaneidade. É nesse sentido que um olhar atento para o modo como pais e mães percebem e lidam com os filhos em processo de construção da identidade adulta mostrou-se pertinente, caracterizando o objetivo da pesquisa. Jablonsky e Martino (2013) apontam a escassez de estudos sobre o tema, especialmente no que diz respeito ao modo como as figuras parentais informam seus filhos acerca do grau de maturidade com que os percebem.

\section{AS LENTES EPISTEMOLÓGICAS}

Os elementos contextuais apresentados permitemnos considerar a transição para a vida adulta na contemporaneidade como uma construção articulada a aspectos de uma realidade compartilhada em constante movimento e transformação. Se, em gerações anteriores, podiam-se observar vivências de juventude inscritas em contextos de maiores estabilidade, previsibilidade e segurança, o que predomina, hoje, é a construção de projetos individuais mais fluidos e inseguros, menos respaldados por experiências parentais que possam servir como modelos (Szapiro \& Resende, 
2010). A ampliação das possibilidades de vivências tradicionalmente associadas à adultez, seja no que diz respeito às relações de intimidade, seja no que tange à construção de percursos profissionais, exige a adoção de uma visão de mundo que abranja a complexidade dos fenômenos humanos, o caráter intersubjetivo da construção da realidade e a instabilidade da vida. Tais aspectos constituem os pilares do paradigma sistêmico (Vasconcellos, 2009), lente epistemológica que subsidiou a realização da pesquisa.

À luz da perspectiva de Morin (2011), a complexidade, "tecido de acontecimentos, ações, interações, retroações, determinações e acasos que constituem nosso mundo fenomênico" (p. 13), toma os fenômenos como impassíveis de uma compreensão total, global e única, dado que podem ser apreendidos sob múltiplas perspectivas, correspondendo a cada uma delas um conjunto de elementos constituintes relevantes e uma forma singular de articulação entre os mesmos. Disso resulta a realidade como construção e não como algo que existe a priori à espera de ser descoberto. Segundo Vasconcellos (2009), sendo múltiplas as perspectivas, a instabilidade se coloca como marca dessa construção, assumindo a possibilidade do acaso e, portanto, da imprevisibilidade dos fenômenos. Por outro lado, na medida em que a construção da realidade pressupõe a assunção de pontos de vista, torna-se clara a importância, e mesmo a necessidade, da participação ativa dos indivíduos, da articulação entre eles, da intersubjetividade.

\section{ASPECTOS CONCEITUAIS}

Considerar a passagem para a adultez como um processo revela-se condição sine qua non para a compreensão das visões teóricas contemporâneas acerca da construção da identidade adulta. No Brasil e fora dele, os estudos acadêmicos parecem afastar-se da proposição de definições "fechadas" sobre o que significa tornar-se adulto, reconhecendo a miríade de possibilidades de ser aberta pelas transformações tecnológicas e sociais contemporâneas, que engendram diversas possibilidades de trajetórias e projetos de vida.

Arnett (2005), por exemplo, nomeia como adultez emergente a fase do ciclo vital compreendida entre os 18 e os 25 anos, caracterizando-a como um período que envolve a exploração da identidade com foco no si mesmo. Trata-se de uma fase instável e de experimentação, viabilizada pela não-obrigatoriedade de o jovem assumir compromissos entendidos pelo autor como típicos da vida adulta: o casamento, a parentalidade e a independência financeira. A licença para a vivência desse processo viria, segundo a teoria em questão, da própria sociedade, em uma espécie de moratória social, por meio da qual as famílias teriam legitimado o papel de compreender, apoiar e subsidiar o jovem em sua transição para a vida adulta.

Em Portugal, Brandão, Saraiva e Matos (2012) discordam da concepção de adultez emergente como fase da vida agraciada pela liberdade de experimentação. Com base em um estudo comparativo entre os processos de transição para a vida adulta em Portugal e no Brasil, as autoras destacam o contexto socioeconômico como principal elemento em função do qual os indivíduos desenham seus projetos e trajetórias individuais, não da maneira como bem entendem, mas sim em função de "escolhas possíveis no seio das oportunidades estruturais" (p. 310). A adultez emergente constituiria, assim, um sintoma, uma resposta dos indivíduos às condições oferecidas pelas sociedades para a elaboração de percursos de vida, e não um período de construção da identidade adulta ampliado em virtude da livre experimentação de oportunidades.

No Brasil, Camarano (2006) parece alinhar-se às ideias produzidas pelo estudo português. Se, de um lado, sustenta como marcos legitimadores da condição adulta as inserções familiar e laboral, ou seja, a constituição de um núcleo familiar próprio e o ingresso efetivo no mercado de trabalho, de outro reconhece que os processos que viabilizam tais inserções passam hoje, por profundas mudanças. Assim, para a autora, mais do que os processos de transição para a adultez, é a própria vida adulta que se encontra em transição. Os diferentes caminhos para lidar com as mudanças em curso configurariam, nesse sentido, movimentos de individualização das trajetórias de vida, não em virtude de uma maior liberdade, mas em função do desamparo experimentado pela sociedade brasileira frente à ausência de garantias institucionais.

Tal desamparo é também abordado por Borges e Magalhães (2009), para as quais o apoio emocional oferecido pela família aos filhos em transição para a adultez goza de particular importância na contemporaneidade, na qual as instituições não mais se mostram capazes de oferecer condições estruturais satisfatórias para a consecução de projetos de vida. Nesse sentido, a coabitação entre pais e filhos ao longo desse processo não seria, necessariamente, disfuncional, podendo configurar-se como ponto de apoio e absorção dos impactos gerados por eventuais tentativas fracassadas na construção da identidade adulta.

A contextualização da transição para a vida adulta de uma perspectiva intergeracional torna clara a importância de atentarmos para o caráter mútuo 
do processo de tornar-se adulto. Dele participa não apenas o jovem, com seus projetos individuais, mas também o sistema parental, que precisa adaptar-se ativamente às mudanças reveladas pelos descendentes, ressignificando a própria parentalidade. Tal aspecto é discutido por Berthoud (2000), que localiza nesse estágio do ciclo de vida familiar a tarefa de reconstruir a relação parento-filial, tendo em vista o reconhecimento do "filho-outro": passa a caber aos pais não mais saber o que devem ser, mas sim o que podem ser. Segundo Cerveny e Berthoud (2009), nessa fase do ciclo vital familiar, denominada "fase madura", as relações hierárquicas tendem a ser relativizadas, levando pais e filhos a reconhecer-se como pares.

Outros autores atentam para o caráter mútuo da construção da identidade adulta dos filhos no sistema familiar. McCullough e Rutenberg (1995) ressaltam a importância de que os pais tenham "bem resolvida" a própria maturidade em relação às respectivas famílias de origem, a fim de que o lançamento dos filhos no mundo não seja percebido como perda. Shapiro (1991) nota a associação disfuncional que fazem algumas famílias entre a autonomia, conquista essencial à identidade adulta, e a perda de relações de proximidade afetiva com a família de origem. Nesses sistemas familiares, o comportamento mais independente e autônomo dos filhos é interpretado como distanciamento afetivo, desvinculação emocional, e não como um movimento necessário e saudável para tornar-se indivíduo.

A autonomia é também discutida por Aylmer (1995), que a inclui no grupo de habilidades essenciais à maturidade, juntamente com a confiança, a competência, a esperança e a autoestima. Outros autores, como Berthoud (2000), abordam o comportamento independente em relação aos pais como importante sinalizador da identidade adulta. Com efeito, os termos "independência" e "autonomia" se fazem fortemente presentes nos estudos sobre a adultez, sendo frequentemente usados de forma confusa e indiscriminada. Constituem, contudo, definições distintas e interligadas, o que se mostra esclarecido por Morin (2011). Para este autor, a autonomia, apreendida como condição psicológica e cognitiva de realizar escolhas e de por elas responsabilizar-se, presume certa medida de independência. Contudo, paradoxalmente, alimenta-se de dependência, na medida em que "nós dependemos de uma educação, de uma linguagem, de uma cultura, de uma sociedade, dependemos claro de um cérebro, ele mesmo produto de um programa genético, e dependemos também de nossos genes" (p.66).

Aplicada à dinâmica de funcionamento do sistema familiar, a compreensão moriniana de autonomia torna possível problematizar a vinculação da ideia do "tornar-se adulto" à separação física do indivíduo em relação à sua família de origem. Tal ideia por muito figurou inclusive no campo da Psicologia e apenas recentemente vem sendo questionada. Aylmer (1995), por exemplo, define o estágio do ciclo de vida do jovem adulto como "aquele período de tempo em que o indivíduo deixou sua família de origem, em termos físicos, se não emocionais, mas ainda não estabeleceu uma família de procriação" (p. 169). Jablonsky e Martino (2013), ao contrário, consideram a possibilidade de uma separação simbólica, efetivada pelo jovem ao eleger o próprios valores e realizar as próprias escolhas em relação à vida cotidiana.

Após observar a importância conferida por esses autores às relações intergeracionais ao longo do processo de transição para a vida adulta, podemos recorrer a Bowen (1991) para mais satisfatoriamente compreender o funcionamento humano implicado no maior ou menor êxito obtido nesse processo. A teoria familiar boweniana inscreve-se na Psicologia Sistêmica, sendo a própria família compreendida como um sistema emocional caracterizado pelo que o autor denomina massa indiferenciada do ego familiar. Partindo da unidade emocional constituída pela família de origem, o processo de construção do indivíduo, do qual é parte integrante a transição para a vida adulta, dar-se-ia segundo um movimento de diferenciação, ou seja, de aquisição progressiva de autonomia emocional com relação a essa família. Nesse processo estariam envolvidas as duas forças vitais que, segundo Kerr e Bowen (1988), governam o funcionamento dos indivíduos em suas inter-relações, embrionariamente nas relações familiares: a individualidade e a vinculação, que se articulam de modo a viabilizar o desempenho mais ou menos autônomo de cada membro dentro e fora da família.

A capacidade de cada indivíduo para bem administrar as forças vitais opostas que o impulsionam, ora para um funcionamento mais autodeterminado (individualidade), ora para uma organização psicológica mais dependente das expectativas de outros significativos (vinculação), dimensionará sua diferenciação. Diferenciar-se não significa, portanto, romper absoluta e definitivamente com o núcleo familiar; consiste, antes, em uma oportunidade, para os jovens em transição para a adultez, "escolherem emocionalmente aquilo que levarão da família de origem, aquilo que deixarão para trás e aquilo que irão criar sozinhos" (Carter \& McGoldrick, 1995, p. 16). Esse movimento não é individual; ao contrário, implica a reorganização do sistema familiar de modo geral, do que participam tanto os filhos, com a construção de 
funcionamentos mais autônomos, quanto os próprios pais, que aí se veem obrigados a redefinir os próprios limites na relação com seus descendentes. Neste ponto, a organização estrutural familiar (Minuchin, 1982) torna-se relevante, contribuindo para explicar o sucesso ou o fracasso nos processos de diferenciação.

Assim como a abordagem intergeracional boweniana, a concepção da família de um ponto de vista estrutural alinha-se à perspectiva sistêmica, atentando para a funcionalidade da organização familiar com base na inter-relação entre os membros. A família, compreendida como um sistema, abriga relações que envolvem todos os seus membros, assim como interações segmentadas. Nesse sentido, no interior do sistema familiar operam subsistemas, como o conjugal e o parental, que inscrevem entre si fronteiras mais ou menos demarcadas, o que irá determinar a funcionalidade das relações entre os membros, assim como do funcionamento individual dos mesmos. Uma fronteira nítida, mais funcional, articula com sucesso o estabelecimento de limites e a permeabilidade nas relações, promovendo interações capazes de, simultaneamente, garantir o intercâmbio de afeto e cuidado e preservar a individualidade dos membros que compõem o sistema. Fronteiras rígidas, por sua vez, costumam tornar esse intercâmbio difícil, favorecendo o distanciamento entre os membros da família, que tendem a comportar-se na base do "cada um por si". Uma fronteira difusa, ao contrário, estimula o emaranhamento do sistema familiar: as funções e papeis se complementam ou se confundem, a interferência em questões individuais acentua-se e, em decorrência, a diferenciação dos indivíduos pode ver-se comprometida.

\section{MÉTODO}

Em consonância com as dimensões de complexidade, instabilidade e intersubjetividade que sustentam o paradigma sistêmico (Vasconcellos, 2011), uma possível compreensão da forma como as figuras parentais percebem e lidam com a transição de seus filhos para a vida adulta foi construída por meio de uma pesquisa qualitativa, realizada com base em entrevistas semiestruturadas. $\mathrm{O}$ estudo foi realizado após aprovação do Comitê de Ética em Pesquisa da universidade de filiação das pesquisadoras, em 08/11/2010, sob o Protocolo n ${ }^{\circ} 373 / 2010$.

\section{Participantes}

A escolha dos participantes deu-se em função dos objetivos da pesquisa, por meio da seleção intencional da amostra, cabível em estudos qualitativos. Com efeito, segundo Creswell (2010), “a ideia que está por trás da pesquisa qualitativa é a seleção intencional dos participantes ou dos locais (...) que melhor ajudarão o pesquisador a entender o problema e a questão de pesquisa" (p. 212, grifo do autor). A definição do número de participantes obedeceu ao critério de saturação para a composição de amostras, observandose alguns aspectos que, segundo Charmaz (2005), não podem ser ignorados: 1) as observações empíricas se mostram cobertas pelas categorias de análise; 2) as informações coletadas e a análise apresentam relação consistente; 3) as categorias de análise viabilizadas pela amostra são capazes de oferecer novos insights sobre o tema.

Os pais e mães escolhidos como participantes atendiam aos seguintes critérios de inclusão: a) têm diploma de graduação, mesmo que no momento da pesquisa não se encontrassem no exercício da profissão; b) são pais de indivíduos com curso de graduação concluído havia pelo menos dois anos; c) são pais de indivíduos que, quando da realização da pesquisa, tinham entre 25 e 30 anos, sendo o limite inferior desse intervalo etário correspondente ao definido pela Organização das Nações Unidas como idade de ingresso no mercado de trabalho (BarrientosParra, 2004) e o limite superior, correspondente à idade média em que o indivíduo atinge a maturidade biológica (Papalia et al., 2010).

Abaixo se encontra uma breve descrição das famílias participantes, com características gerais tidas como relevantes para a compreensão dos resultados que serão apresentados. Os nomes reais dos participantes foram substituídos por nomes fictícios, a fim de preservar a identidade dos envolvidos:

- Família 1: foram entrevistados José Carlos, 57 anos, engenheiro agrônomo, e Lúcia, 54 anos, psicóloga. Embora o casal tenha quatro filhos, apenas Sandro, 27 anos, casado, engenheiro agrônomo, atendia aos critérios de inclusão. À época da realização da entrevista, Sandro sustentava-se financeiramente e não residia com os pais.

- Família 2: Ricardo, 58 anos, professor, e Nilva, 59 , artista plástica, constituem o casal entrevistado. Ambos os filhos, que residiam com os pais e sustentavam-se parcialmente quando da entrevista, atendiam aos critérios de inclusão: Nilton, 30 anos, solteiro, graduado em Rádio e TV, e João, 25 anos, solteiro, formado em Educação Física.

- Família 3: apenas Elza, 63 anos, psicóloga e mãe solteira, foi entrevistada. O filho único André, 28 anos, solteiro, engenheiro químico, residia com a 
mãe e sustentava-se parcialmente com o próprio salário quando da realização da entrevista.

- Família 4: foi entrevistado o casal Elton, 57 anos, advogado, e Regina, 56 anos, graduada em Direito, mas que tornou-se dona de casa, abdicando do exercício da profissão. Ambos os filhos, Camila, 29 anos, casada, advogada, e André, 26 anos, solteiro, publicitário, preenchiam os critérios de inclusão, sustentavam-se parcialmente e não residiam com os pais à época da entrevista.

- Família 5: Marta, 65 anos, viúva e graduada em Administração de Empresas, foi entrevistada. A única filha, Laura, atendia aos critérios de inclusão por ocasião da entrevista: 26 anos, solteira, nutricionista, residia com a mãe e sustentava-se parcialmente.

- Família 6: Claudia, 57 anos, bancária e divorciada, foi entrevistada. Mãe de três filhos, dos quais apenas Gisele, bióloga de 26 anos, solteira, enquadrava-se nos critérios de inclusão. A filha não residia com a mãe e sustentava-se financeiramente.

- Família 7: foram entrevistados Jonas, 58 anos, fisioterapeuta, e Alice, 56 anos, fisioterapeuta aposentada. Atendiam aos critérios de inclusão ambos os filhos: Tomás, arquiteto de 29 anos, solteiro, que se sustentava financeiramente e não residia com os pais, e Fábio, 25 anos, solteiro e também arquiteto, que morava com os pais e sustentava-se parcialmente.

\section{Instrumentos e procedimentos}

O convite aos participantes em potencial foi realizado via telefone ou e-mail, oportunidade na qual se confirmava o preenchimento dos critérios de inclusão. Não houve recusa à participação por parte de nenhum dos convidados. O encontro, marcado nesse primeiro contato após a aceitação do convite, ocorreu na residência dos entrevistados e teve início com a assinatura individual do Termo de Consentimento Livre e Esclarecido (TCLE). Em seguida, foi solicitado aos participantes que preenchessem uma ficha de informações familiares (no caso dos casais, uma única ficha para cada casal), que contemplava aspectos tidos como necessários para contextualizar as experiências vividas por pais e filhos: idade dos envolvidos, informações sobre graduação/profissão dos mesmos, local de moradia e grau de independência econômica dos filhos. Passou-se, então, à entrevista semiestruturada propriamente dita.

Segundo Kvale e Brinkmann (2009), o uso de entrevistas permite co-construções de possíveis realidades, o que dimensiona a importância da competência do pesquisador na condução das conversações com os sujeitos de pesquisa. Também Denzin e Lincoln (2006) atribuem à interação entre pesquisado e pesquisador um valor primordial, na medida em que é com base nela que a compreensão e a interpretação dos significados atribuídos a um fenômeno, características centrais da pesquisa qualitativa, tornam-se possíveis. O estudo aqui apresentado tinha como questões norteadoras as seguintes perguntas: 1) Conte $(\mathrm{m})$ um pouco como foi a sua experiência de transição para a vida adulta. Em que momento da vida você(s) considera(m) haver se tornado uma pessoa adulta?; 2) Como percebe $(\mathrm{m})$ a transição do(a) seu(sua) filho(a)? Você(s) o(a) enxerga(m) como um(a) adulto(a)?; 3) De um modo geral, independente da experiência individual ou de seu(sua) filho(a), o que você(s) acredita $(\mathrm{m})$ que precisa acontecer na vida de uma pessoa para que ela possa ser considerada adulta? Os encontros duraram, em média, 1 hora e 30 minutos, e foram conduzidos pela pesquisadora. Cada entrevistado ou casal de entrevistados respondeu a uma única entrevista, número que se revelou suficiente para atingir os objetivos propostos.

Em um segundo momento, foi enviado e-mail solicitando aos participantes (um representante por família) que respondessem ao questionário de classificação econômica elaborado pela Associação Brasileira de Empresas de Pesquisa (ABEP). Esse pequeno questionário aplica o Critério de Classificação Econômica Brasil (CCEB), que divide a população brasileira urbana em classes econômicas segundo o grau de instrução do chefe de família e o poder de compra de seus membros. Após a obtenção das respostas, a classe econômica relativa a cada família foi anotada nas respectivas fichas de informações familiares. As famílias 1,2 e 4 pertenciam ao estrato A2; as famílias $3,5,6$ e 7 , ao estrato B1.

\section{Análise e interpretação}

Após a transcrição das gravações e a organização das observações de campo, a análise e interpretação das informações deu-se em três níveis: $1^{\circ}$ ) apreensão de grandes temas, com base em um olhar criterioso sobre as entrevistas; $2^{\circ}$ ) identificação de frases, nomeadas unidades de análise, sinalizadoras dos significados atribuídos pelos entrevistados aos processos de transição para a vida adulta no contexto dos respectivos grandes temas; $3^{\circ}$ ) construção de categorias de significado, apresentadas junto aos grandes temas com base nos quais foram construídas, como díades emergentes da análise circular.

O caráter circular da análise realizada baseou-se na perspectiva de Ricoeur (1986) sobre o processo de 
interpretação. Para o autor, esse processo busca ir além do dito diretamente, logrando trabalhar relações não aparentes entre significados. A atribuição de diferentes graus de importância a certos aspectos é feita por meio de conjecturas: como uma totalidade singular, o texto pode ser abordado de várias faces, mas não de todas simultaneamente e, ao reconstruí-lo, sempre o fazemos de uma perspectiva. Emergem, então, interpretações mais prováveis, validadas em uma lógica da incerteza pela argumentação, base, segundo o autor, para uma ciência do individual. Tais interpretações expressam significados e permitem "ouvir" os dados, em um movimento que se inicia no plano descritivo e atinge o plano compreensivo, assim como parte do concreto para o mais abstrato. Nesse processo, na presente pesquisa, emergiram as seguintes díades, compostas pelos grandes temas (primeiro item da díade) e pelas categorias de significado a cada um deles relacionada (segundo item da díade): a) acontecimento versus processo $e$ a responsabilidade como um valor; b) família e contexto $e$ a construção da identidade adulta; c) visões ambivalentes $e$ a maturidade da interdependência.

\section{RESULTADOS E DISCUSSÃO}

Com base no processo de análise e interpretação, podemos afirmar, de modo geral, que notáveis diferenças entre os percursos de pais e filhos confirmaram a ideia, defendida entre sociólogos (Groppo, 2000) e antropólogos (Debert, 2010), de que as reflexões sobre a construção da adultez pedem novas referências. Presentes nos processos de transição dos pais, as expectativas de linearidade e constância, bem como de cumprimento de certas tarefas desenvolvimentais em determinado tempo e espaço, não mais se ajustam à realidade dos jovens em tempos atuais, resultando inadequadas ao contexto de transição dos filhos.

\section{Grandes temas e categorias de significado}

Após um olhar criterioso sobre as entrevistas, foi possível reunir três grandes temas presentes na perspectiva das figuras parentais: acontecimento $\times$ processo, família e contexto e visão ambivalente sobre o tornar-se adulto. À medida que eram captadas frases significativas, presentes nas falas dos participantes e aqui denominadas unidades de análise, oferecia-se consistência aos temas ora apreendidos, sinalizando, simultaneamente, o modo pelo qual as experiências dos pais e mães em relação aos temas em questão eram atribuídas de significado. A seguir, são apresentadas as díades construídas, compostas pelos grandes temas e pelas categorias de significado a eles associadas.
1. Acontecimento versus processo e a responsabilidade como um valor: a observação atenta dos assuntos abordados permitiu-nos identificar, na experiência das figuras parentais, a percepção da transição para a adultez como uma mudança de fase no ciclo vital claramente representada por acontecimentos específicos. Quando questionados sobre as vivências individuais de transição, sobre o momento em que passaram a considerar-se como adultos, os participantes apontaram a independência financeira, o casamento e a saída da casa dos pais como eventos que marcaram a própria transição. A responsabilidade como competência sine qua non para a legitimação do "ser adulto" já aparecia subjacente a tais acontecimentos:

"foi durante a faculdade, $2^{\circ}$ ano de faculdade..., que eu acho que eu comecei a dar aula (...) A responsabilidade era maior. Ter meu dinheiro, saber controlar, poder comprar uma coisinha, sair..." (Jonas)

"Eu acho que quando me casei (...). Porque aí você se dá conta que tudo vai depender de você. Desde o fósforo até a comida." (Claudia)

"Ah, eu já senti minha transição. Foi bem marcante, né. Foi exatamente quando eu fui pros Estados Unidos. Porque eu sempre fui ensinado a tomar decisões próprias, mas eu sempre tinha alguém com quem trocar ideia. E quando eu fui pros Estados Unidos, apesar dessa família ser muito próxima, algumas decisões eu tinha que tomar." (Elton)

Ao responder à segunda questão da entrevista, passando a referir-se ao modo como enxergavam os filhos na transição para a vida adulta, pais e mães revelaram um redimensionamento na relação processo-acontecimento, tornando-se este último consideravelmente desinvestido da importância de que gozara na experiência de transição dos progenitores. Vejamos os discursos de Ricardo e de Marta:

"Acho que se a gente desaparecesse pra sempre da vida deles [Nilton e João], acho que eles conseguiriam com as próprias pernas, se virar. Então, se o conceito de adulto for esse, eu posso dizer que eles são adultos." (Ricardo)

"Porque eu sempre trabalhei, mas nunca deixei que ela [Laura] trabalhasse. E como ela não teve 
condição de arrumar um emprego, assim, eu vejo que ela cresceu muito. Ela é muito responsável, sempre foi muito responsável, mas hoje eu vejo que ela cresceu muito." (Marta)

Enfim, quando questionados sobre o que consideram necessário acontecer, de modo geral, para que o indivíduo possa ser considerado adulto, a responsabilidade consolida-se como valor:

"Eu acho que, assim, a pessoa precisa ter responsabilidade de algum jeito, de alguma coisa. Ou estudando, ou trabalhando. Eu acho que é esse ponto aí, porque ela tem que caminhar com as próprias pernas." (Marta)

"Que [a pessoa] se responsabilize pela própria vida. Isso quer dizer o que? Ah, que cuide das suas coisas.” (Elza)

A atribuição de uma menor importância aos acontecimentos como marcos de transição para a vida adulta mostra-se coerente com o movimento de revisão das certezas modernas que ganha espaço na contemporaneidade. Tal movimento torna justa e necessária a busca de novas referências de pensamento e ação, e isto é identificado no discurso daquelas figuras parentais que, na ausência das mesmas referências concretas que ora lhes confirmaram a própria condição adulta, buscaram reconstruir em seus filhos o significado da adultez, encontrando na responsabilidade o valor que eles carregam.

2. Família e contexto e a construção da identidade adulta: a mudança de foco manifestada pela maioria dos entrevistados, dos acontecimentos como marcos de transição para a maturidade em direção à responsabilidade como um valor, acompanha as transformações sociais, políticas, culturais e econômicas assistidas desde a década de 1970, período de construção da vida adulta entre os pais, até os primeiros anos deste século XXI, momento de transição dos filhos. Tais transformações resultaram em diferenças contextuais claramente percebidas pelos entrevistados, como se verifica nos comentários de José Carlos e Elza, quando questionados sobre o modo como percebem os filhos na passagem para a vida adulta:

"A vida é mais difícil, os requerimentos são maiores... Eu estudei em escola pública, eles não. Eles sabem que os filhos deles vão ter que ter... vão ter que prevenir mais." (José Carlos)
"Acho que ta bem mais dificil. Também porque... o que se necessita para se sustentar é muito mais, hoje você tem que pagar pros filhos escola, né, que meus pais não tiveram que pagar. Saúde, plano de saúde, se tornou um negócio imprescindivel, assim. Seguro de automóvel é imprescindivel. Seguro extra, além do INSS (...). Internet, né, toda essa eletrônica que a gente tem disponível, tudo isso custa. Então, além de ter mais estabilidade no emprego, não tinha tanta despesa." (Elza)

Uma vez apreendidas as transformações contextuais e articulando-as ao modo como os pais entrevistados percebem seus filhos, constatamos que, diante da atual relativização dos marcos tradicionais de legitimação da adultez, os processos de passagem para a vida adulta podem ser abordados, hoje, primordialmente em sua dimensão psíquico-emocional, nos termos da diferenciação do indivíduo em relação à família de origem, como um movimento de conquista de autonomia (Bowen, 1991) legitimado pelo exercício hábil da responsabilidade. Entre os filhos dos entrevistados, há tanto aqueles que, já havendo deixado o lar parental ou sendo economicamente independentes, não são considerados pelos pais como plenamente maduros, quanto outros que, ainda residindo com os progenitores e sendo sustentados por eles (mesmo que parcialmente), se acham reconhecidos pelos mesmos em sua adultez. Respondendo à segunda questão proposta na entrevista semiestruturada, os participantes avaliam:

"A Camila [que não mora com a mãe e é financeiramente independente dos pais] eu tenho a impressão que ela precisa de um respaldo. 'Eu vou, eu faço, eu aconteço, mas eu preciso de uma retaguarda.," (Regina)

"Ela [Laura, que mora com a mãe e sustentase parcialmente] é muito responsável, sempre foi muito responsável, mas hoje eu vejo que ela cresceu muito." (Marta)

Esta é, de forma geral, a visão apresentada pelos entrevistados, e que nos permitiu construir a categoria de significado que contempla, na contemporaneidade, a constituição da identidade adulta como um processo validado não mais por referências externas fixas, mas pelo desenvolvimento de competências individuais postas à prova no enfrentamento da complexidade da vida.

3. Visões ambivalentes e a maturidade da interdependência: apesar desse movimento geral capaz de 
atrelar a noção de maturidade à conquista de autonomia, alguns modelos de dinâmica familiar permanecem inalterados. Entre os entrevistados, visões ambivalentes acerca da condição adulta dos filhos lançam luz sobre o fato de a construção da adultez preconizar, em última instância, uma transição entre fases distintas do ciclo vital familiar. Shapiro (1991) lembra que os membros de um sistema familiar podem tanto adaptarse funcionalmente quanto reagir negativamente a esforços de diferenciação. Isso irá depender de como se organiza a estrutura da família em termos de suas fronteiras internas e externas, da capacidade dos pais de ressignificar a parentalidade ao longo do ciclo vital familiar e do grau de dependência emocional entre os membros.

Neste ponto, faz-se útil retornar a Minuchin (1990). Dentre as estruturas familiares possíveis já apresentadas, aquelas com fronteiras difusas tendem a favorecer visões ambivalentes acerca do tornar-se adulto. Tal modelo de estrutura pode encontrar raízes tanto em heranças intergeracionais quanto em fatores externos que, de alguma forma, provoquem alterações no funcionamento desse sistema. Ao referir-se à percepção sobre o filho Sandro (segunda questão da entrevista), Lúcia aponta a busca de afeto nos pais como um comportamento que suscita dúvida quanto à real condição adulta de seu descendente:

“Eu vejo o Sandro bastante responsável, assim, profissionalmente, bastante sério. Mas têm umas coisas assim, alguns momentos, que eu falo 'ai, que crianção, ai, que meninão ainda."

Contudo, essa mesma mãe, que compreende a demanda de afeto proveniente do filho como um aspecto que oblitera a consistência de sua maturidade, esforçase em participar ativamente dos acontecimentos da vida dos filhos em assuntos que envolvem as emoções:

"Eu participo bastante! 'Ah, eu vou buscar não sei quem não sei aonde'. Eu: 'ah, eu vou junto!' E dai eu fico conversando o tempo todo. Mas tem coisa que eu não sei também. (...) Mas da vida pessoal, do relacionamento com a namorada, com a esposa, isso ai eu converso bastante."

A despeito das investidas de Lúcia, não se pode afirmar que Sandro não concluiu seu processo de transição para a maturidade. A percepção da mãe, que ainda recorre aos marcos tradicionais como legitimadores da condição adulta, parece não encontrar em tais marcos indícios de não-transição para a adultez, já que Sandro casou-se, é financeiramente independente e não habita com os pais. Sob o argumento da ligação afetiva, Lúcia parece confundir a busca pelo afeto dos pais com a ausência de maturidade. Esse pensamento reflete uma característica interna do sistema familiar do qual Sandro, José Carlos e Lúcia participam e que aponta para certo grau de emaranhamento.

Processo semelhante, porém assentado sobre outras bases, parece ocorrer na família de Ricardo e Nilva. Enquanto o pai assegura-se da adultez dos filhos Nilton e João recorrendo ao argumento da separação física, a mãe reluta em reconhecer os filhos como efetivamente adultos. Poderíamos haver concentrado esta análise no emaranhamento decorrente de uma herança intergeracional, mas, se assim houvéssemos procedido, estaríamos negligenciando um aspecto central e, entre todos os entrevistados, restrito a essa família: a doença crônica.

Shapiro (1991) lembra que, para além das heranças intergeracionais, fatores externos podem tornar-se agentes estressores que, promovendo o emaranhamento do sistema familiar, resultam em engessar um dado padrão de funcionamento. Rolland (1995) afirma que a doença crônica, por implicar a introdução, no núcleo da família, de um foco de atenção comum, tende a exercer uma força centrípeta sobre o sistema familiar. A intensidade e a frequência dos cuidados com o membro doente organizam os demais em um trabalho em equipe que movimenta a família nos esforços de controle da doença crônica. Como peça essencial de uma engrenagem, cada membro vê-se vinculado aos demais, podendo favorecer um grau significativo de dependência afetiva, inibindo ou dificultando esforços individuais de diferenciação. A anorexia desenvolvida por João, que, aos 15 anos, chegou a pesar 35 quilos, parece guardar relação com a resistência de Nilva em considerar os filhos adultos. Reconhecendo sentir-se bem com a presença de ambos no lar parental, a mãe arrisca "falar por eles", revelando, na relação com os descendentes, atitudes fundadas na força centrípeta, que busca trazer os filhos para o ninho familiar. Em resposta à pergunta "como percebem a transição dos seus filhos? Vocês os enxergam como adultos?", a mãe questiona:

"Você acha que meus filhos têm vontade de morar sozinhos em um apartamento pequenininho? Não! Eles podiam até querer mudar para um apartamento, a gente até ajudar eles a comprar, ou eles comprarem sozinhos. Mas eu não vou acelerar."

Berthoud (2000) torna clara a importância, e mesmo a necessidade, de movimentos de ressignificação do 
"ser pai" e "do ser mãe" no percurso de crescimento dos filhos. Carter e McGoldrick (1995) compreendem o indivíduo adulto como aquele que, longe de realizar um afastamento emocional em relação à família de origem, pois isto seria destrutivo, alcança, junto a ela, um estágio de maturidade da interdependência. Portanto, conforme o termo anuncia, o "tornar-se adulto" não implica essencialmente um movimento individualmente empreendido com vistas ao distanciamento, tanto físico quanto emocional, em relação ao núcleo familiar. Constitui, antes, um processo do qual participam, de forma articulada, todos os membros desse sistema, no sentido de permitir o funcionamento autodeterminado, ainda que conectado, de cada um deles.

\section{CONSIDERAÇÕES FINAIS}

Considerando os resultados da pesquisa, podemos afirmar que a democratização nas relações de intimidade, à medida que atingiu as interações parento-filiais, favoreceu aos pais enxergarem os filhos em suas potencialidades, indicando para estes um progressivo afastamento da obrigatoriedade de ritualizar a transição para a vida adulta por meio dos acontecimentos ora socialmente legitimados como inauguradores da vivência da adultez: o casamento, a independência financeira e a saída do lar parental. Assim, embora a construção do "ser adulto" continue buscando na família seu lócus referencial, encontrase cada vez menos sob a expectativa de configurar-se como um percurso linear e pré-definido, assumindo progressivamente o caráter de um processo orientado pelo valor moral da responsabilidade e legitimado pela aquisição de autonomia. As figuras parentais, dentre os entrevistados, pareceram evoluir na compreensão desse novo sentido, na medida em que, mesmo com base em autorreferências ritualizadas, reconheceram a prevalência da responsabilidade como condição sine qua non para a caracterização do indivíduo adulto.

Em algumas famílias, notamos visões ambivalentes quanto à adultez, mas percebemos aí a interveniência de questões intrafamiliares, como uma organização estrutural emaranhada e a ocorrência de doença crônica. Nesses casos, as dificuldades localizaram-se nas próprias figuras parentais que, confundindo autonomia com desvinculação emocional, puseram ressalvas quanto à efetiva condição adulta de seus filhos.

Não ignoramos que, em contextos intrafamiliares, o conteúdo emocional envolvido na reordenação de funções epapeis individuais, ao longo das transformações que movimentam o ciclo vital das famílias, pode obstaculizar as transições mais previsíveis. No entanto, acreditamos tratar-se de movimentos adaptativos possíveis, no objetivo de construir modos funcionais de significação e ressignificação das vivências cotidianas. Esperamos, com este trabalho, haver contribuído para a ampliação do conhecimento acerca dos processos de transição para a vida adulta neste novo cenário multifacetado, que tende a confrontar o psicólogo com a necessidade de compreender o desafio de pais cujos filhos se encontram nessa fase do ciclo de vida, frente à necessidade de ressignificação da parentalidade.

\section{REFERENNCIAS}

Arnett, J. J. \& Tanner, J. L. (Ed.). (2005). Emerging Adults in America. Coming of Age in the $21^{\text {st }}$ Century. Washington D.C.: American Psychological Association.

Aylmer, R. C. (1995). O lançamento do jovem adulto solteiro. In Carter, B. \& McGoldrick, M., As Mudanças no Ciclo de Vida Familiar: uma estrutura para a terapia familiar (pp. 169-183). Porto Alegre: Artmed.

Barrientos-Parra, J. (2004). O estatuto da juventude: instrumento para o desenvolvimento integral dos jovens. Revista de Informação Legislativa, 41(163), 141-152.

Berthoud, C. M. E. (2000). Re-significando a parentalidade: desafio para toda uma vida. (Tese de Doutorado, Pontifícia Universidade Católica de São Paulo, São Paulo).

Boeing, L. G. (2011). Construindo a vida adulta. (Dissertação de Mestrado, Universidade Federal de Santa Catarina, Florianópolis).

Borges, C. C. \& Magalhães, A. S. (2009). Transição para a vida adulta: autonomia e dependência na familia. Psico, 40(1), 42-49.

Bowen, M. (1991). De la familia al individuo: la diferenciación del sí mismo en el sistema familiar. Buenos Aires: Paidos.

Brandão, T., Saraiva, L., \& Matos, P.M. (2012). O prolongamento da transição para a idade adulta e o conceito de adultez emergente: especificidades do contexto português e brasileiro. Análise Psicológica, 30(3), 301-312.

Camarano, A.A. (Org.). (2006). Transição para a vida adulta ou vida adulta em transição? Rio de Janeiro: Ipea.

Carter, B. \& McGoldrick, M. (1995). As mudanças no ciclo de vida familiar: uma estrutura para a terapia familiar. In Carter, B. \& McGoldrick, M., As mudanças no ciclo de vida familiar: uma estrutura para a terapia familiar (pp. 7-29). Porto Alegre: Artmed.

Cerveny, C. M. O. \& Berthoud, C. M. E. (Orgs.). (2009). Família e ciclo vital: nossa realidade em pesquisa. São Paulo: Casa do Psicólogo.

Charmaz, K. (2005). Grounded theory in the 21st century. Applications for advancing social justice studies. In Denzin, N., \& Lincoln, Y. S., The Sage handbook of qualitative research (pp. 507-535). Thousand Oaks, London, New Delhi: Sage Publications.

Creswell, J. W. (2010). Projeto de pesquisa: métodos qualitativo, quantitativo e misto. Porto Alegre: Artmed.

Critério de Classificação Econômica Brasil. (2008). Associação Brasileira de Empresas de Pesquisa. Recuperado de http://www. abep.org/novo/Content.aspx?ContentID=301

Debert, G. G. (2010). A dissolução da vida adulta e a juventude como valor. Horizontes Antropológicos, 16(34), 49-70.

Giddens, A. (1993). A transformação da intimidade: sexualidade, amor e erotismo nas sociedades modernas. São Paulo: Editora da Universidade Estadual Paulista (UNESP). 
Groppo, L. A. (2000). Juventude: ensaios sobre sociologia e história das juventudes modernas. São Paulo: Difel.

Henriques, C. R., Féres-Carneiro, T., \& Ramos, E. (2011). Ajustes entre pais e filhos adultos coabitantes: limite e transgressão. Psicologia em Estudo, 16(4), 531-539.

Hime, F. A. (2004). A biografia feminina e a história das relações amorosas: o voo da fênix. (Tese de Doutorado, Pontifícia Universidade Católica de São Paulo, São Paulo).

Jablonsky, J. F. \& Martino, S. (2013). A qualitative exploration of emerging adults' and parents' perspectives on communicating adulthood status. The Qualitative Report, 18(73), 1-12.

Kerr, M. \& Bowen, M. (1988). Family evaluation. New York: WW Norton \& Company.

Kvale, S. \& Brinkmman, S. (2009). InterViews: learning the craft of qualitative research interviewing. Thousand Oaks, New Delhi, London, Singapore: Sage Publications.

McCullough, P. \& Rutemberg, S. (1995). Lançando os filhos e seguindo em frente. In Carter, B. \& McGoldrick, M. As mudanças no ciclo de vida familiar: uma estrutura para a terapia familiar (pp. 248-268). Porto Alegre: Artmed.

Mendonça, M. P. G. (2007). Processo de transição e percepção de adultez: análise diferencial dos marcadores identitários em jovens estudantes e trabalhadores. (Dissertação de Mestrado, Faculdade de Psicologia e Ciências da Educação, Porto).

Minuchin, S. (1990). Famílias: funcionamento \& tratamento. Porto Alegre: Artes Médicas.

Morin, E. (2011). Introdução ao pensamento complexo. Porto Alegre: Sulina.

Pais, J. M. (2005). Ganchos, tachos e biscates: jovens, trabalho e futuro. Lisboa: Âmbar.

Papalia, D. E., Olds, S. W., \& Feldman, R. D. (2010). Desenvolvimento Humano. Porto Alegre: AMGH.
Ricoeur, P. (1986). Do texto a acção. Ensaios de Hermenêutica II. Porto: Rés Editora.

Rolland, J. S. (1995). Doença crônica e o ciclo de vida familiar. In Carter, B. \& McGoldrick, M. As mudanças no ciclo de vida familiar: uma estrutura para a terapia familiar (pp. 373-392). Porto Alegre: Artmed.

Romanelli, G. (2003). Autoridade e poder na família. In M. C. B. Carvalho (Org.). A familia contemporânea em debate (pp. 73-88). São Paulo: Cortez.

Shapiro, E. R. (1991). Individual change and family development: individuation as a family process. In Falicov, C. J. Family transitions: continuity and change over the life cycle (pp. 159180). New York: Guilford Press.

Szapiro, A. M. \& Resende, C. M. A. (2010). Juventude: etapa da vida ou estilo de vida? Psicologia \& Sociedade, 22(1), 43-49.

Vasconcellos, M. J. E. (2009). Pensamento Sistêmico: o novo paradigma da ciência. Campinas: Papirus.

Zanetti, S. A. S. \& Gomes, I. C. (2009). A ausência do princípio de autoridade na família contemporânea brasileira. Psico, 40(2), 194-201.

Autores:

Clarissa Magalhães Rodrigues - Doutorando, Pontifícia Universidade Católica de São Paulo.

Ida Kublikowski - Doutor, Pontifícia Universidade Católica de São Paulo.

Endereço para correspondência:

Clarissa Magalhães Rodrigues

Av. Independência, 940 - sala 52

CEP13.419-155 Piracicaba, SP, Brasil

E-mail: clarissamagalhaes.psico@gmail.com

Recebido em : 13.01.14

Aceito em: 24.06.14 